\title{
Unilateral proptosis as a clinical presentation in primary angiosarcoma of skull
}

\author{
SAMRUAY SHUANGSHOTI,' PRACHA CHAYAPUM, \\ NITAYA SUWANWELA, ${ }^{3}$ AND CHARUS SUWANWELA ${ }^{2}$
}

From the 'Departments of Pathology, ${ }^{2}$ Surgery, and ${ }^{3}$ Radiology, Faculty of Medicine, Chulalongkorn University, Bangkok, Thailand

SUMmARY A case is reported of unilateral proptosis of the left eyeball as a unique clinical presentation of primary angiosarcoma of the skull involving the sphenoid and frontal bones and roof of the orbit on the left side of a 32-year-old man. The intraosseous, extradural nonencapsulated, and friable tumour contained cytoplasmic factor VIII-related antigen. After complete removal of the tumour the patient has been well for 10 months of the follow-up period. This case brings the total number of reported primary angiosarcomas of the cranium to nine. All patients were male and most of them were young. The average age was 24 years. The frontal bone seems to be the site of predilection for cranial angiosarcomas. Surgical extirpation, radiation, or combined surgical removal and radiation have been used for treating angiosarcoma of the skull with variable results. It is suggested that angiosarcoma of the skull has a worse prognosis than angiosarcoma of bones other than the cranium because the patient may die of secondary neoplastic involvement of the brain.

Primary new growths of the cranial bones constitute only $2.6 \%$ of 500 primary bone tumours in one series ${ }^{1}$ and $2.4 \%$ of 1610 primary bone neoplasms in another collection. $^{2}$ Angiosarcomas are extremely rare among primary malignant tumours of the skull; only eight acceptable cases have appeared in the literature. ${ }^{3-9}$ In this communication we report an intraosseous angiosarcoma involving the sphenoid and frontal bones as well as the roof of the orbit and causing unilateral exophthalmos. The latter becomes a unique clinical presentation for angiosarcoma arising in the cranium.

\section{Case report}

A 32-year-old man was admitted to hospital because of progressive left proptosis without other associated symptoms or signs for one year.

EXAMINATION

With a slit-lamp the left eye was $15 \mathrm{~mm}$ compared with $12 \mathrm{~mm}$ for the right eye by measuring from the

Correspondence to Professor Samruay Shuangshoti, Department of Pathology, Chulalongkorn Hospital, Bangkok 10500, Thailand. orbital rim to the most anterior aspect of the cornea. Ocular movements were normal bilaterally. Each pupil, $2 \mathrm{~mm}$ in diameter, was reactive to light. Visual acuity, visual field, eye ground, and the rest of the physical examination were unremarkable.

A plain $x$-ray of the skull showed destruction of the lesser wing of the sphenoid bone and posterior wall of the orbit on the left side. Computed tomographic (CT) scans of the cranium gave the following findings on the left side: proptosis, and destruction and expansion of the sphenoid and frontal bones in relation to an enhanced lesion which appeared to extend into the orbit (Figs. 1A, B).

\section{OPERATION}

A left frontotemporal craniotomy disclosed an intraosseous, extradural, non-encapsulated, highly vascular, and friable tumour involving the lesser and greater wings of the sphenoid bone, frontal bone, and roof of the orbit. It was firmly adherent to the adjacent dura mater. A small part of the lesion was also adherent to the superior aspect of the bulbar fascia of the left eyeball. The entire neoplasm was removed along with the affected parts of bones, 

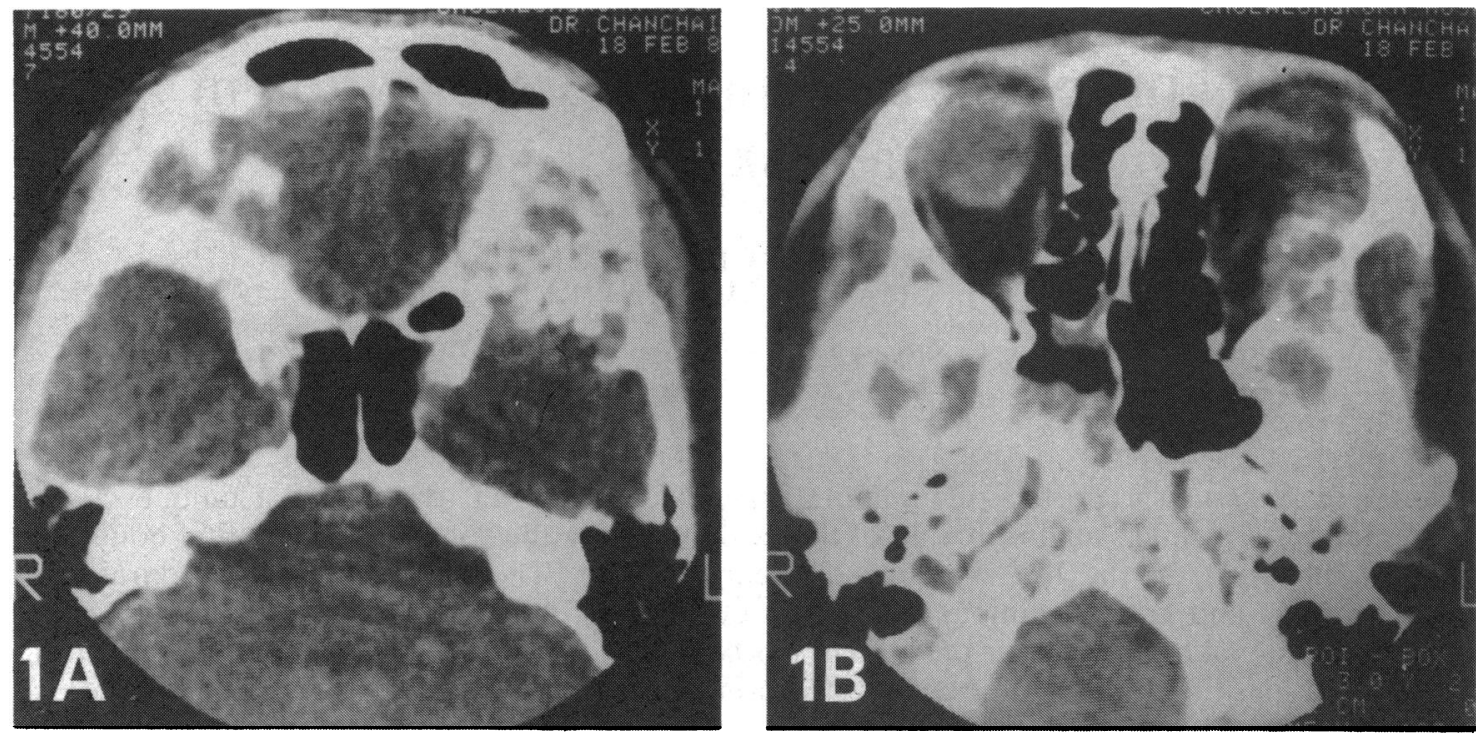

Fig. 1 CT scan of skull. A: Plain CT scan at the base of the cranium shows destruction and expansion of the lesser wing of the sphenoid and frontal bones on the left side with involvement of the diploic space. B: The enhanced mass extends into the posterolateral part of the left orbit.

bulbar fascia, and dura mater. The dural defect was grafted with temporal fascia. There was profuse bleeding, which required 10 units of blood for transfusion. The adjacent part of the brain was free from tumour infiltration. The patient recovered uneventfully.

\section{PATHOLOGICAL EXAMINATION}

Multiple pieces of haemorrhagic tissue with fragments of bones, about $2.5 \mathrm{ml}$ in combined volume, were fixed in $10 \%$ formalin. The largest fragment of tumour, $2.5 \mathrm{~cm}$ in greatest dimension, was attached partly to dura mater; it had a spongy cut surface. These tissue fragments were embedded in paraffin and stained with haematoxylin and eosin (H-E). Gomori's silver impregnation for reticulin fibres was also done. Moreover, the peroxidase-antiperoxidase (PAP) indirect immunohistochemical method was used on paraffin-embedded tissue sections for localisation of factor VIII-related antigen, a protein synthesised primarily by endothelium,,${ }^{10-12}$ in the tumour cells. A fragment of the spleen was similarly processed as a control.

Microscopically the lesion was a highly vascular neoplasm invading bone and dura mater (Fig. 2). Neoplastic blood vessels were lined by plump cuboidto-ovoid endothelial cells having pleomorphic and hyperchromatic nuclei. Scattered individual vessels, anastomosing vascular channels, and papillary formations were noted (Fig. 3). Nevertheless large blood-filled spaces lined by endothelial cells that were not strikingly atypical were also observed. The stroma between recognisable blood vessels was composed of loose myxomatous tissue that contained? stellate cells as well as elongate or spindle-shaped cells (Fig. 4A) and neoplastic cells similar to those lined the vascular channels. These extravascular tumour cells tended to be in clusters or disseminated individually (Fig. 4B). Gomori's silver impregnation disclosed that the tumour cells were within the reticulin sheath of the vessels in the area where vascular spaces were present (Fig. 4C). Reticulin fibres also surrounded clusters of the neoplastic cells in the zone where the tumour cells were grouped within the myxomatous matrix (Fig. 4D). Encircling of the argyrophilic fibres round the individual tumour cells was not seen. Factor VIII-associated antigen was often present in the cytoplasm of the tumour cells that lined the vascular lumina and in the myxomatous stroma (Fig. 5). Hence the endothelial nature of the tumour cells was confirmed immunohistochemically.

The pathological diagnosis was an angiosarcoma involving the sphenoid and frontal bones and roof of the orbit on the left side and invading the adjacent dura mater and superior aspect of the bulbar fascia of the left eyeball.

POSTOPERATIVE COURSE

The patient was discharged 17 days after admission to hospital. CT scans of the skull one month and nine months after surgical intervention revealed no evidence of tumour. There was a decrease in the size 

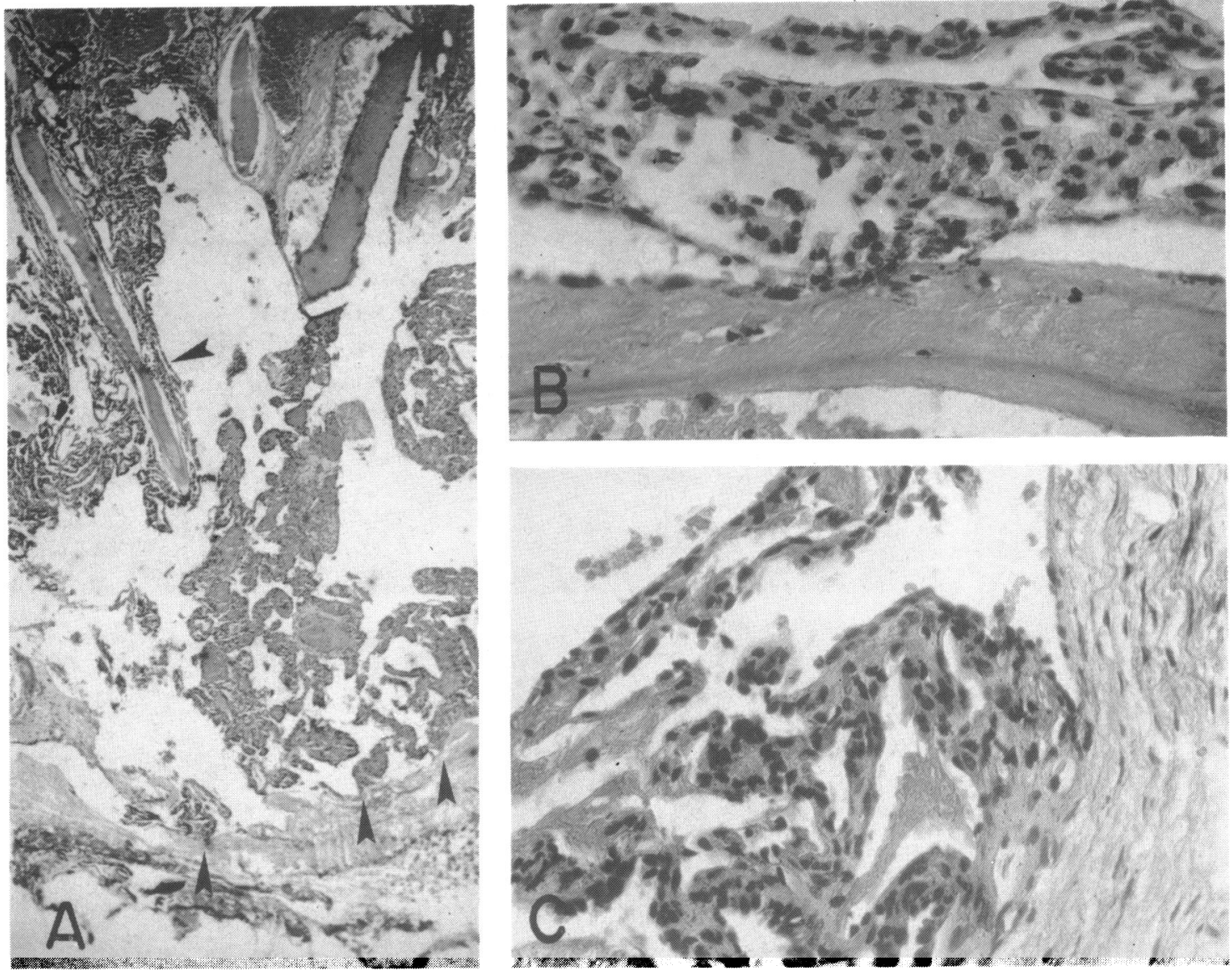

Fig. 2 Invasion of angiosarcoma into bone and dura mater. A: The angiosarcoma invades bone trabecula (upper arrowhead) and dura mater (lower arrowheads) $(H-E, \times 44)$. B: The area indicated by the upper arrowhead in $A$ demonstrates focal invasion of the tumourcells into the edge of the bone trabecula $(H-E, \times 348)$. C: The region indicated by the left lower arrowhead in $A$ exhibits infiltration of the neoplastic cells into the dura mater $(H-E, \times 348)$.

of the shadow of soft tissues at the operative site. The left exophthalmos was improved. The patient could perform his daily work as usual.

\section{Discussion}

GENERAL CONSIDERATIONS

The term 'angiosarcoma' as used here is regarded as synonymous with the following terms found in the literature: angioendothelioma, malignant angioma, angiofibrosarcoma, haemangioblastoma, angioblastic sarcoma, malignant haemangioendothelioma, haemangioendothelioblastoma, malignant angioblastoma, haemangioendotheliosarcoma, intravascular endothelioma, malignant endothelioma, and malignant bone aneurysm. ${ }^{13} 14$

Anastomosing vascular channels lined by pleomorphic endothelial cells which often form papillae are diagnostic of angiosarcoma. ${ }^{8}{ }^{14}$ These histopathological features were also seen in our patient's tumour. Moreover, the endothelial nature of the tumour cells is further confirmed by localisation of cytoplasmic factor VIII-related antigen. Hence the pathological diagnosis of the angiosarcoma is considered as unequivocal in our case.

The main intraosseous position with minimal infiltration of the bulbar fascia, as noted surgically, makes us conclude that the current angiosarcoma is primarily intraosseous, with secondary invasion into the superior aspect of the bulbar fascia. It is hard to imagine reciprocally that a small primary angiosarcoma of the latter will extend widely to become an intraosseous lesion within the sphenoid and frontal bones as well as the orbital roof. A lesion of bones forming the orbit may cause proptosis. 

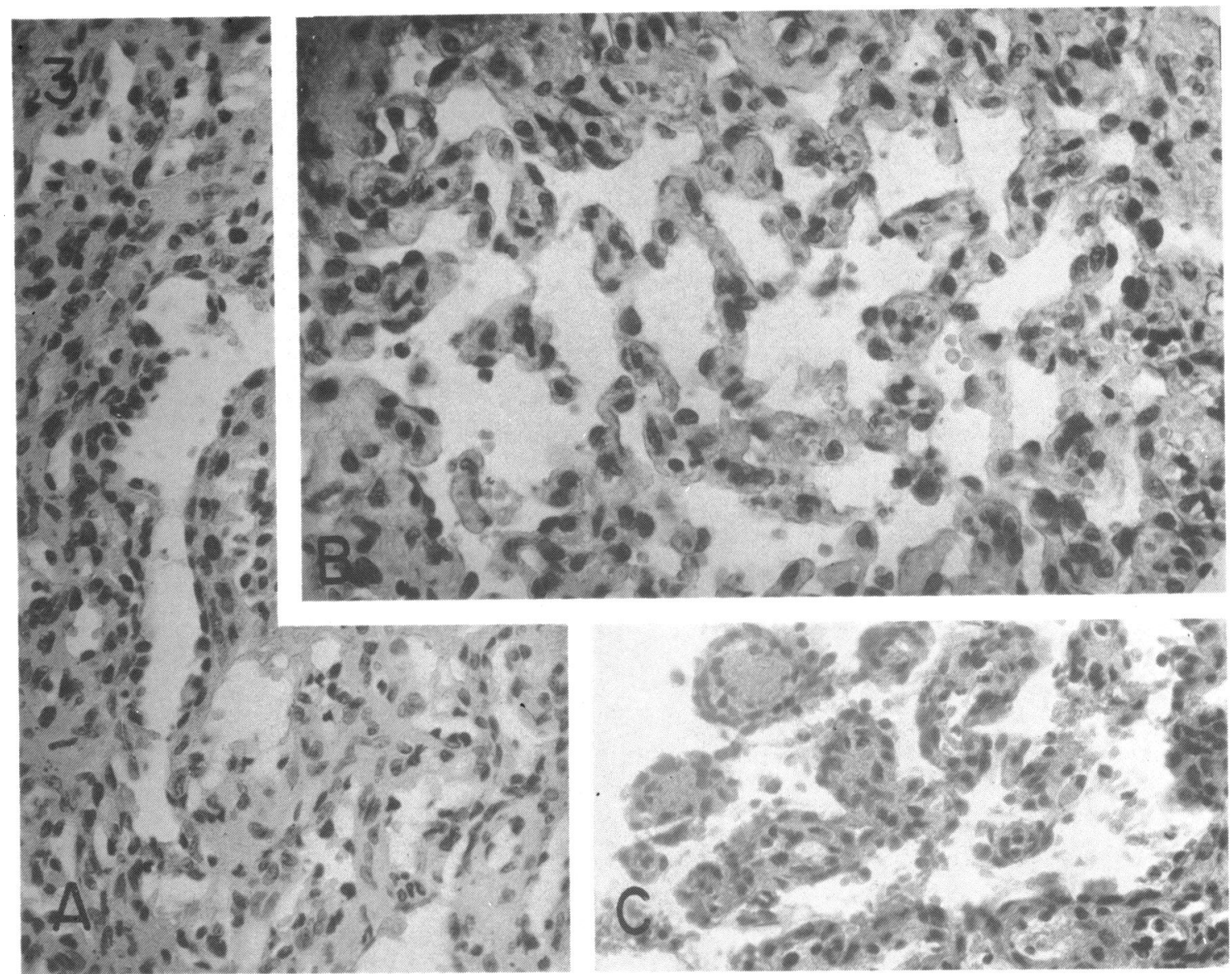

Fig. 3 Histopathology of angiosarcoma $(H-E, \times 337$ each $)$. A: Blood vessels are lined by neoplastic endothelium with pleomorphic and hyperchromatic nuclei. B: Anastomosing cords of pleomorphic endothelial cells are shown. C: Papillary formations of endothelial tumour cells are shown.

\section{DIFFERENTIAL DIAGNOSIS}

The present angiosarcoma of bones must be distinguished from such lesions as meningioma, haemangiopericytoma, and primary intravascular papillary endothelial hyperplasia. Attachment to the dura mater, bony invasion, and papillary formations suggest that the tumour is a meningioma, especially the papillary type. However, the absence of the tumour capsule, meningocytes, cellular whorls, and intranuclear vacuoles, and the presence of cytoplasmic factor VIII-related antigen in the tumour cells exclude a meningioma. ${ }^{15}{ }^{16} \mathrm{We}$ also do not consider our patient's tumour to be a haemangiopericytoma of the meninges ${ }^{17}$ or of the orbit. ${ }^{18}$ The absence of reticulin fibres round individual tumour cells is not a feature of haemangiopericytoma. Moreover, the neoplastic cells were mainly intravascular rather than perivascular. Hence they were not peri- cytes. According to Nadji et al. ${ }^{11}$ tests for factor VIIIassociated antigen are persistently negative in cells of haemangiopericytoma.

Primary intravascular papillary endothelial hyperplasia may mimic an angiosarcoma. ${ }^{19.21}$ However, the endothelium in this condition is benign, as the name 'hyperplasia' implies. Although the overgrown endothelium in this condition may form intravascular papillae, it lacks nuclear pleomorphism. By contrast, the current lesion had endothelium that showed pleomorphic nuclei and invaded the surrounding tissues. Hence the lesion should be named as angiosarcoma rather than as primary intravascular papillary endothelial hyperplasia.

\section{BRIEF REVIEW OF LITERATURE}

To our knowledge 12 angiosarcomas of the skull have been reported. $.^{3-9} 1422-24$ However, four of them are 

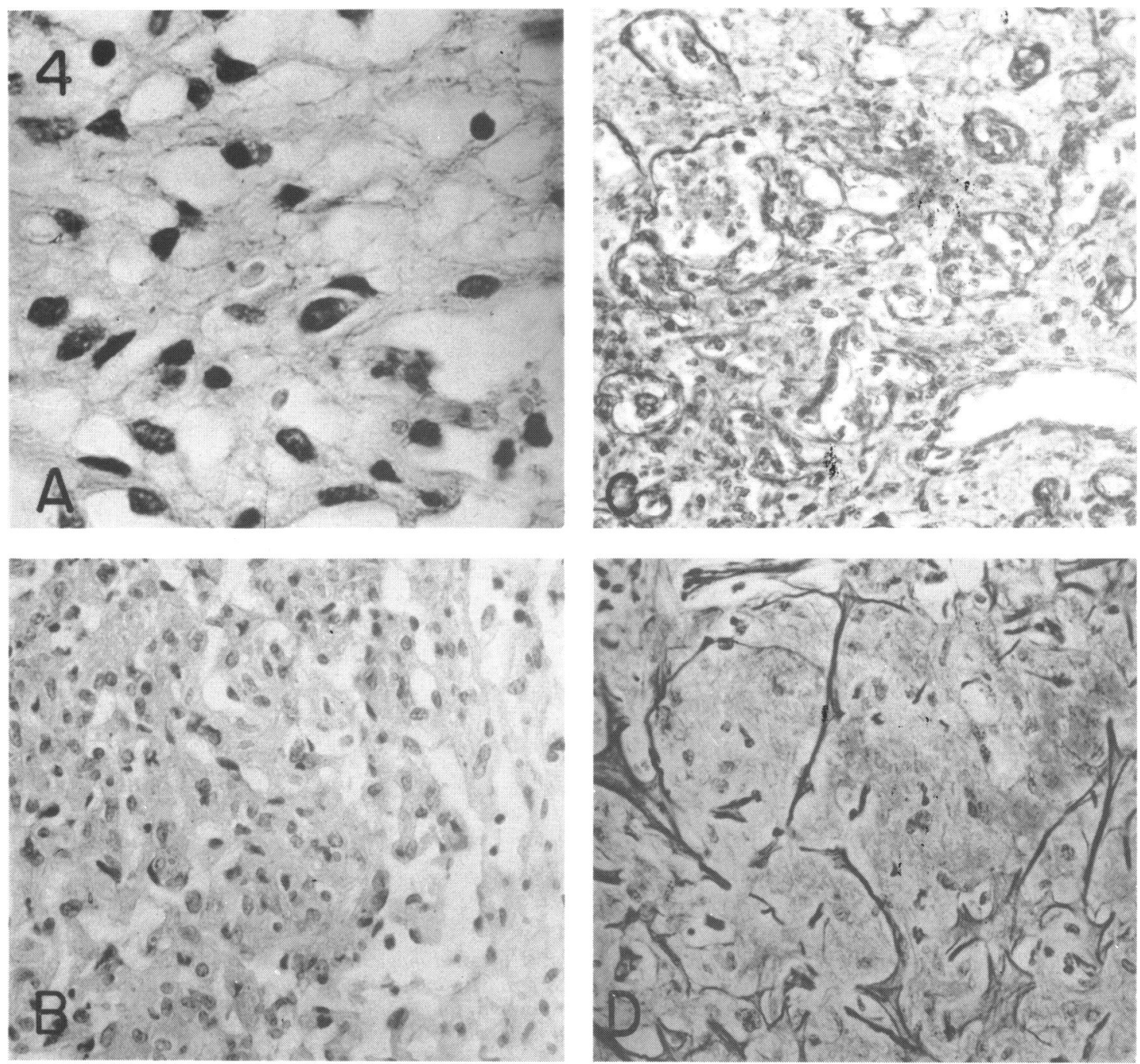

Fig. 4 Stroma and pattern of reticulin fibres in angiosarcoma. A: Stellate and spindle-shaped cells lie within the loose myxomatous matrix of the tumour $(H-E, \times 886)$. B: The tumour cells are clustered in the loose myxomatous stroma $(H-E$, $\times 354)$. C: Reticulin fibres surround blood vessels that are lined by neoplastic endothelium. Some blood vessels are partly filled by endothelial cells (Gomori's silver impregnation, $\times 354)$. D: Clusters of the tumour cells in the myxomatous matrix are surrounded by a few argyrophilic fibres (Gomori's silver impregnation, $\times 354$ ).

excluded herewith because of inadequate pathological confirmation of the lesions. ${ }^{1422-24}$ Thus nine angiosarcomas of the cranium including our case are considered in this discussion. ${ }^{3-9}$ The youngest patient was 3 months old ${ }^{4}$ and the oldest was 50 years. ${ }^{8}$ Most patients were young. Three were children less than 8 years old. ${ }^{128}$ The average age was 24 years. All persons were male. A local mass or swelling was the usual clinical presentation. Only our patient presented with unilateral proptosis.

The tumour involved the frontal bone in four cases, ${ }^{57-9}$ parietal bone in two cases, ${ }^{6}$ temporal bone in one case, ${ }^{3}$ sphenoid and frontal bones as well as the orbital roof in one case (current patient), and maxilla in one case. ${ }^{4}$ Thus the frontal bone seems to be the favoured site for angiosarcomas of the skull.

Resection, radiation, or combined resection and radiation were frequently used in treating the angiosarcomas of the cranium, with variable results. Surgical treatment seems to give encouraging results in some patients, in that they have been alive for 27 months ${ }^{4}$ and $3 \frac{1}{2}$ years, ${ }^{8}$ but one patient died post- 

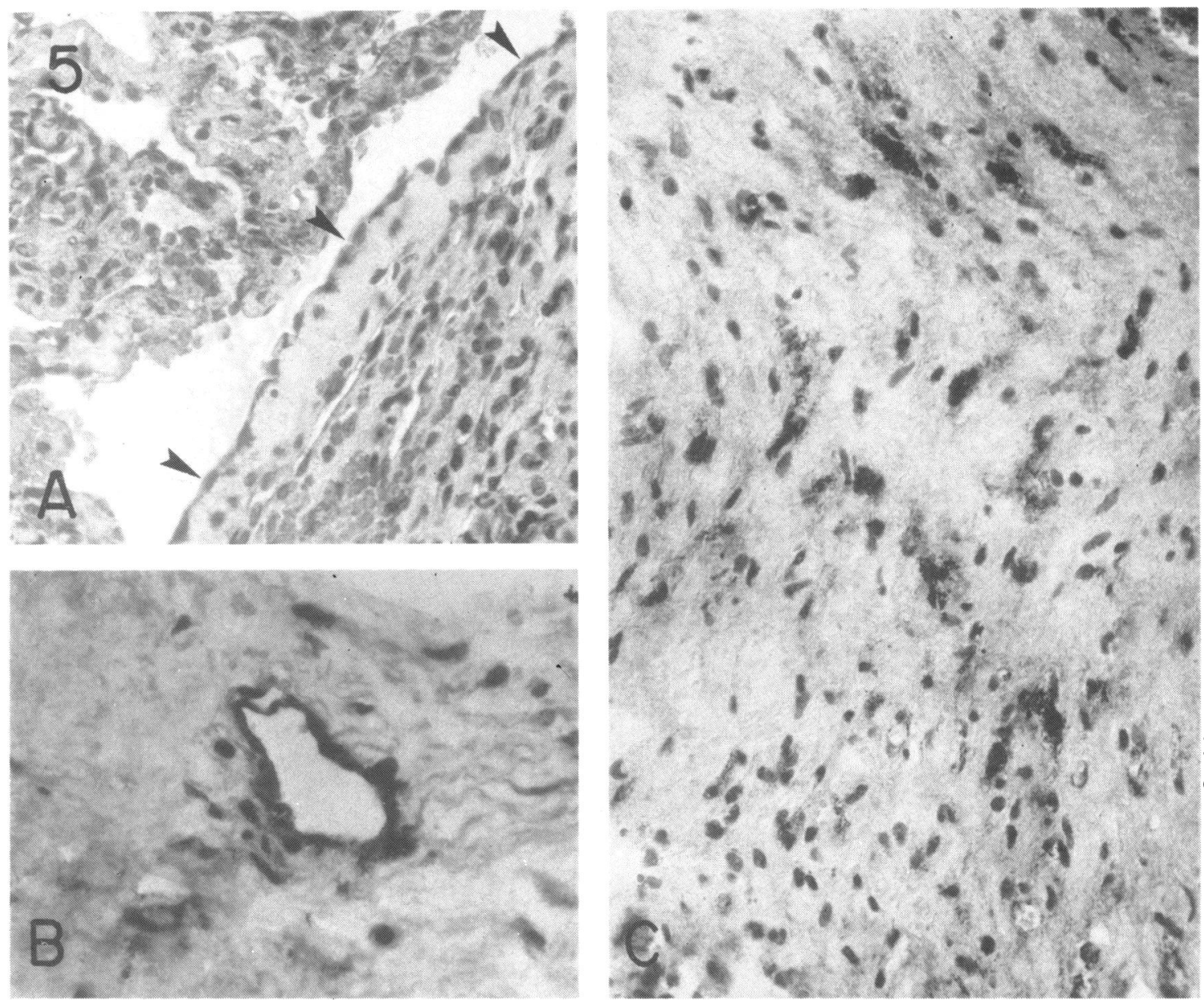

Fig. 5 PAP indirect immunohistochemical localisation of factor VIII-related antigen in angiosarcoma $(\times 354$ each $)$. A: The arrowheads point toward a row of endothelial cells that show weak positivity for factor VIII-related antigen in the perikaryon. B: A neoplastic blood vessel with endothelial cytoplasm of strong positivity for factor VIII-associated antigen lies within the loose myxomatous matrix. C: Neoplastic endothelial cells with strong positivity for cytoplasmic factor VIII-related antigen are disseminated randomly in the loose myxomatous interstitium.

operatively. ${ }^{8}$ A boy who received high doses of radiation for primary and recurrent angiosarcomas of the frontal bones has been well for 12 years, ${ }^{9}$ but another boy lived only 9.5 months with radiotherapy. ${ }^{3}$ Chow et al..$^{7}$ believed that a 21 -year-old man who had had an angiosarcoma of the frontal bone was cured by combined radiation and resection. The patient first had a biopsy and a course of radiotherapy totalling $6000 \mathrm{cGy}$ over a six-week period. Seven months later he underwent resection, when the tumour site including the surrounding bone and dura mater was removed en bloc. Pathologically, only fibrosis and suture granuloma were seen. ${ }^{7}$ Nevertheless we believe that angiosarcoma of the skull may have a worse prognosis than angisarcoma of bones other than the cranium, because the tumour may secondarily involve the brain and the patient dies with increased intracranial pressure, as did the boy reported on by Kinkade. ${ }^{3}$

Professor Samruay Shuangshoti is in receipt of a grant from the Medical Section, Anandhamahidol Foundation, 1985-8, Bangkok, Thailand.

\section{References}

1 Geschickter CF. Primary tumours of the cranial bones. Am J Cancer 1936; 26: 155-80.

2 Vandenberg HJ Jr, Coley BL. Primary tumours of the cranial bones. Surg Gynecol Obstet 1950; 90: 602-12.

3 Kinkade JM. Angiosarcoma of the petrous portion of the temporal bone: report of a case. Ann Otol Rhinol Laryngol 1948; 57: $235-40$.

4 Henny FA. Angiosarcoma of the maxilla in a 3 month old infant: report of case. J Oral Surg 1949; 7: 250-2. 
5 Case record of the Massachusetts General Hospital: case 46092. $N$ Engl J Med 1960; 262: 467-73.

6 Hartman WH, Stewart FW. Hemangioendothelioma of bone: unusual tumour characterised by indolent course. Cancer 1962 ; 15: 846-54.

7 Chow RW, Wilson CB, Olsen ER. Angiosarcoma of the skull: report of a case and review of the literature. Cancer 1970; 25: $902-6$.

8 Unni KK, Ivins JC, Beabout JW, Dahlin DC. Hemangioma, hemangiopericytoma, and hemangioendothelioma (angiosarcoma) of bone. Cancer 1971; 27: 1403-14.

9 Larsson SE, Lorentzon R, Boquist L. Malignant hemangioendothelioma of bone. J Bone Joint Surg 1975; 57A: 84-9.

10 Jaffe EA. Endothelial cells and biology of factor VIII. $N$ Engl J Med 1977; 296: 377-83.

11 Nadji M, Gonzalez MS, Castro A, Morales AR. Factor VIIIrelated antigen: an endothelial cell marker. Lab Invest 1980; 42: 139.

12 Burgdorf WHC, Mukai K, Rosai J. Immunohistochemical identification of factor VIII-related antigen in endothelial cells of cutaneous lesions of alleged vascular nature. Am J Clin Pathol 1981; 75: 167-71.

13 Garcia-Moral CA. Malignant hemangioendothelioma of bone: review of world literature and report of two cases. Clin Orthop 1972; 82: 70-9.

14 Huvos AG. Bone tumours: diagnosis, treatment and prognosis. Philadelphia: Saunders, 1979: 358-68.
15 Shuangshoti S, Hongsaprabhas C, Netsky MG. Metastasizing meningioma. Cancer 1970; 26: 832-41.

16 Kasantikul V, Shuangshoti S. Intracranial papillary and glandular meningiomas: report of 2 cases. J Med Assoc Thai 1985; 68: 276-81.

17 Goellner JR, Laws ER Jr, Soule EH, Okazaki H. Hemangiopericytoma of the meninges: Mayo Clinic experience. Am J Clin Pathol 1978; 70: 375-80.

18 Jakobiec FA, Howard GM, Jones IS, Wolff M. Hemangiopericytoma of the orbit. Am J Ophthalmol 1974; 78: 816-34.

19 Salyer WR, Salyer DC. Intravascular angiomatosis: development and distinction from angiosarcoma. Cancer 1975; 36: 995-1001.

20 Clearkin KP, Enzinger FM. Intravascular papillary endothelial hyperplasia. Arch Pathol Lab Med 1976; 100: 441-4

21 Kuo T, Sayers P, Rosai J. Masson's 'vegetant intravascular hemangioendothelioma', a lesion often mistaken for angiosarcoma: study of seventeen cases located in the skin and soft tissues. Cancer 1976; 38: 1227-36.

22 Jelsma F. Primary tumours of the calvaria: with special consideration of the clinical problem. Springficld: Thomas, 1959: 101-4.

23 Dahlin DC. Bone tumours: general aspect and data on 6,221 cases. 3rd ed. Springfield: Thomas, 1981: 10-1, 344-55.

24 Voorhies RM, Sundaresan N. Tumours of the skull. In: Wilkins RH, Rengachary SS, eds. Neurosurgery. New York: McGrawHill, 1985: 1: 984-1001.

Accepted for publication 21 June 1987. 